\title{
IS PROBLEM SOLVING, OR SIMULATION MODEL SOLVING, MISSION CRITICAL?
}

\author{
Ray J. Paul \\ Tillal Eldabi \\ Jasna Kuljis \\ Simon J. E. Taylor \\ Centre for Applied Simulation Modelling (CASM) \\ School of Information Systems, Computing and Mathematics \\ Brunel University \\ Uxbridge, Middlesex UB8 3PH, UK
}

\begin{abstract}
How do we consider problems and models in the practice of simulation? It is our possibly contentious observation that simulation model solving seems to be more critical to the mission of simulation modeling than problem solving. Inspired by the theme of this year's Winter Simulation Conference, we ask the question, "Is problem solving, or simulation model solving, mission critical?" To investigate this we look at three perspectives, those of the textbook, the article and the editorial. The textbook perspective is the balance of the "traditional" view of simulation presented by the academic textbook against practical experience. The article perspective is a classification of papers published in four leading simulation journals in the year 2004 (ACM TOMACS, SIMULATION, Simulation Modelling Practice and Theory, and Simulation \& Gaming). The editorial perspective is a discussion of editorial policy presented by the same journals. Our findings show that our observation is not contradicted.
\end{abstract}

\section{INTRODUCTION}

In the long experience of the first author, one not contradicted by the lesser but fine experiences of the co-authors, simulation model solving seems to be a more critical to those pursuing the mission of simulation modeling than problem solving. Our viewpoint on this emerging worry is as follows. The mission of simulation is about problem solving, assisting, understanding, facilitating, the handling of change, etc. This usually involves a simulation model. Models are fun, enticing peacock devices that are money earners. Problems only exist if they have owners. A problem only exists for as long as its owners believe they still have a problem they want help with. If the owners decide they know what to do, there is no problem. Hence,
As simulation modelers, which are we more interested in? Solving the problem or the model? Consider the following: a model is the analyst's baby, and the nurturing and protecting of it makes the model more important than the problem. After all, the problem is the customer's baby, and one's own baby is always prettier, brighter and better than other babies. Is this true? Are simulation modelers so protective of their own creation they would rather concentrate on the model and not the problem? For the sake of debate we take the stance that this is so and seek to find evidence of practically based advice against this. To this end, and in keeping with the theme of this year's Winter Simulation Conference, this paper asks the question, "Is problem solving, or simulation model solving, mission critical?"

To seek an answer to this question we consider three perspectives, those of the textbook, the article and the editorial. The first of these, the textbook perspective, is intended to represent the balance of the "traditional" view of simulation presented by the academic textbook against our practical experiences. The second of these, the article perspective, is a classification of papers published in four leading simulation journals in the year 2004 (ACM TOMACS, SIMULATION, Simulation Modeling Practice and Theory, and Simulation \& Gaming). The third and final of these, the editorial perspective, is a discussion of editorial policy presented by the same journals.

Our paper is structured as follows. In section 2 we consider the perspective of the simulation textbook. Section 3 presents a perspective derived from an analysis of publications from our leading simulation journals. We then consider the perspective of the editorial policies of the four journals in Section 4. In Section 5 we draw together our findings. Section 6 attempts to answer our question. Section 7 concludes the paper with some final remarks to continue the debate. 


\section{A TEXTBOOK PERSPECTIVE}

Let us take a textbook perspective of simulation. Simulation Modeling and Analysis by Averill M. Law and W. David Kelton is probably the best selling textbook in our field (Law and Kelton, 2000). It is now in its third edition and is regularly updated. It is widely used and cited by educators, researchers and practitioners; indeed we recommend this book to our students. The text well supports problem solving with detailed presentations of, for example, systems modeling, valid, credible and appropriately detailed model building, random number generation and statistical techniques. An approach to a simulation study is also suggested (Figure 1). Briefly, step 1 is defined as problem formulation where one is concerned with issues such setting the objectives of the study and the specific issues to be considered as well as the assessment of the resources available for such a study. Step 2 concerns the collection of data if it exists and the creation of a conceptual model. Step 3 validates the data along side a developing conceptual model. Step 4 constructs the computer model based on a conceptual model of the system. A pilot run is made in step 5 with verification and validation made in step 6. Experimentation addressed in steps 7 to 10 with the documentation, presentation and implementation of the study's findings rolled up in step 10.

\subsection{A TYPICAL EXPERIENCE?}

As a young academic, Paul educated new simulation modelers by using approaches such as that outlined in figure 1 . These were rational, tidy and convincing to teach. The students, with marginally less experience than the educator, also appreciated the clarity of the step that took you from the formulation of the problem to the results of the study. However, when Paul began to practice simulation consultancy he observed that these tidy approaches did not reflect the untidy world. Law and Kelton hint at this, "Note that a simulation study is not a simple sequential process. As one proceeds with the study, it may be necessary to go back to a previous step." Practical experience has shown Paul that a tidy description of simulation is almost completely irrelevant, if not a fantasy. Consider the following two vignettes taken from Paul's many experiences.

Vignette A: The Definitity of Data "I (Paul) collected 5 digit data on sulfuric acid consumption at each pit in a mining company. Five digits, obviously great accuracy. I went to a pit. I looked for a meter on the acid tank. There was none. A pit worker got on top of the tank and with a large pole measured the height of the acid in the tank. tank. This gave an approximate measure of the tank contents which, when adjusted against the last measurement, gave a difference in 5 digits that looked spuriously accurate."

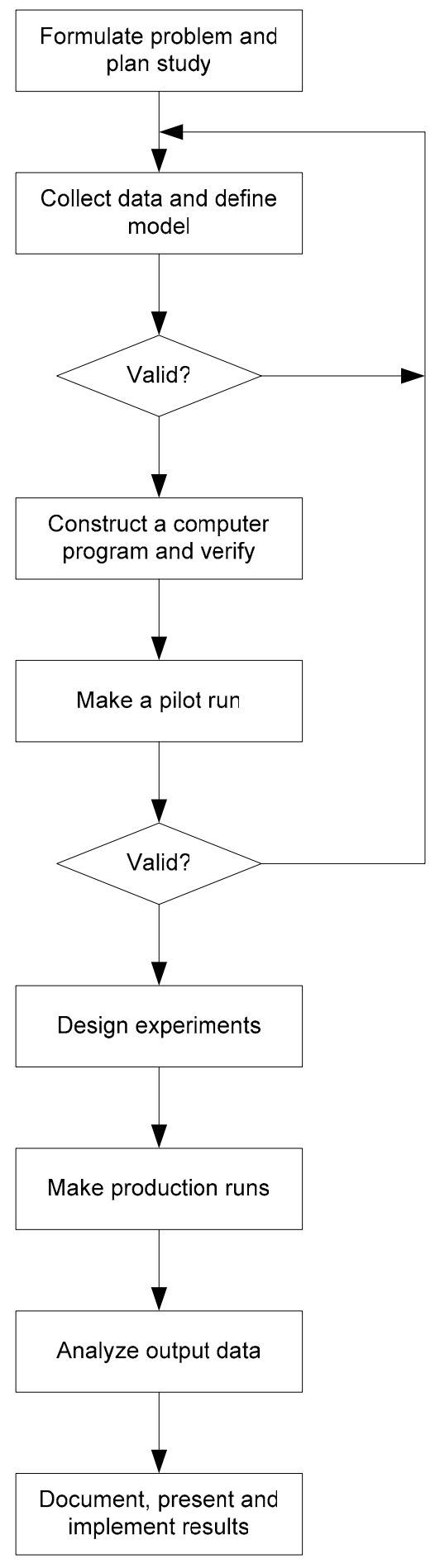

Figure 1: An Approach to Simulation (adapted from Law and Kelton, 2000) 
Paul, Eldabi, Kuljis, and Taylor

Table 1: Practitioner Observation on A Simulation Textbook Approach

\begin{tabular}{|l|l|l|}
\hline Step & Law and Kelton (2000) & Paul, Eldabi and Kuljis (2003) \\
\hline 1 & Formulate problem and Plan the study & $\begin{array}{l}\text { Problems have owners. They do not understand what the problem is. If they } \\
\text { did, they would make decisions. Hence problem formulation is wrong }\end{array}$ \\
\hline 2 & Collect data and define a model. & What data? How relevant and accurate is it. The model is wrong \\
\hline 3 & $\begin{array}{l}\text { Conceptual model valid? Goto 4, else } \\
\text { return to 2. }\end{array}$ & The conceptual model cannot be valid (this can rarely be even attempted). \\
\hline 4 & $\begin{array}{l}\text { Construct a computer program and ver- } \\
\text { ify. }\end{array}$ & Computer programs cannot be verified. The computer program is wrong \\
\hline 5 & $\begin{array}{l}\text { Make pilot runs. } \\
\text { Programmed model valid? Goto 7, else } \\
\text { return to 2. }\end{array}$ & The programmed model cannot be valid. The programmed model is wrong. \\
\hline 7 & Design experiments. & The experiments are wrong \\
\hline 8 & Make production runs. & The production runs produce wrong outputs \\
\hline 9 & Analyze output data. & The analysis is wrong \\
\hline 10 & Document, present, and use results. & The results are wrong \\
\hline
\end{tabular}

Vignette B: When the problem is understood, stop! "One of my students collected data on a paintshop that had massive work in progress (Hlupic and Paul, 1994). The paintshop included an overhead gantry carrying the parts that had to go through cleaning, drying, spraying and annealing. The industrial engineers saw that she had measured the speed of the gantry inaccurately. The student held her ground; she had used the stopwatch accurately enough. Sophisticated gantry speed measurement equipment proved she was right, the gantry was running at $90 \%$ of its proper operating speed. With the gantry speeded up, the work in progress immediately started to diminish, as did interest in the student and the simulation."

The above two excerpts from one practitioner's career serve to illustrate common fallacies in "tidy" simulation approaches. Table 1 presents practically motivated observations on the 10 steps in Figure 1 (Paul, Eldabi and Kuljis, 2003). Simulation is usually resorted to because the problem is not well understood. We might therefore assume that a practitioner's knowledge of the problem is wrong. The 10 steps become a debating device between the practitioner and the problem owners, constantly backtracking, especially to step 1 , with the aim to get an ever closer understanding or appreciation of what the problem really is. Eventually the problem owners get to a point where they think they understand the problem and then, ignoring the simulation (and the practitioner!), they go off and make decisions and get on with their lives. This by definition ends the simulation process.

Law and Kelton's textbook remains, however, an excellent treatise on the subject of simulation. We have selected this not to pour scorn on this exceptional work but to use it to begin the answer to our question "Is problem solving, or simulation model solving, mission critical?" We might argue that in our first perspective, works such as Law and Kelton provide the foundation from which practitioners begin their careers. Students leaving educational courses on simulation typically know how to build models and to verify and validate them. They also have some un- derstanding of experimentation and the meaning of results. However, as a student's work is usually, and quite necessarily, based on some textbook problem; their only contact with the "real world" is through the lens of the model. Their limited experience on finishing such a course can only be based on the models that they have created and not on the problems that the models were derived from. It appears that in answer to our question, our first perspective must be that when a simulation practitioner begins their career they have a "natural" bent towards solving the model and not the problem. That is to say simulation textbooks provide an excellent foundation, but where then do students of simulation turn to find what to do when they practice simulation in anger? Where can they find advice that leads them to solve problems and not models? In the next section we consider the role published articles play in finding this advice.

\section{THE ARTICLE PERSPECTIVE}

In the previous section, we have observed that simulation textbooks give a firm but inevitably model-solving rather than problem-solving foundation to simulation modelers. We now turn our attention to the second of our three perspectives as we further attempt to answer our question "Is problem solving, or simulation model solving, mission critical?" Do articles published in our field give a balance that our textbooks cannot?

To investigate this we performed a brief literature survey of a representative sample of articles published in what we consider to be the four leading simulation journals. These are:

- ACM Transactions on Modeling and Computer Simulation (TOMACS) volume 14 (3/4) and volume $15(1 / 2)$

- SIMULATION volume 80(2 to 12 ) and volume 81(1) 
- Simulation Modelling Practice and Theory (SMPT) volume 12(6 to 8 ) and volume 13 (1 to 3 )

- Simulation \& Gaming volume 8(2 to 4$)$ and volume 9(1)

In each article we looked for evidence that the article addressed issues concerning a real-world problem. We defined "real-world problem" as being one that had a stakeholder owner specifically identified in the article. Of these we then looked for evidence that the authors of the article had solved the problem. Within these we then looked for evidence of implementation, that the problem solution had been carried through to the system in which the real-world problem existed. Our results are shown in Table 2. Figures 3 and 4 show the results graphically for the percentage of papers with stakeholder problem owners and the attempted solutions against implementations.

As can be seen in figure 2, in our sample the number of articles concerning non-problem solving topics far outweigh those that do. Overall $90.7 \%$ of these concerned non "real-world" problems by our definition with TOMACS having none at all and SIMULATION marginally outperforming the rest. However, as shown in figure 3 , of the $9.3 \%$ that did address real-world problems $80 \%$ of these papers considered some real world solution, i.e. we might argue that in these cases the problem was solved and not the model. However, in all cases no "follow through" implementation could be identified.

So what does this perspective offer us in terms of our question? Of the papers considering real-world problems, ones with identifiable stakeholders, we are reassured that $80 \%$ of these showed evidence of some solution to the problem and not just to the model developed to solve the problem. However, a little alarmingly in this sample set there was no evidence of any implementation of the solution. In terms of our question we might now feel a little heartened that on firm foundations built on education textbooks our students might turn to good advice from published articles. But what of implementation? Taking a harsh view one might argue that none of these solutions were ever implemented! The solutions presented in the articles might therefore be of little, if any worth. This argument is very much a side issue as our major observation of simulation publication is that in our sample set just over $90 \%$ of articles addressed problems with no stakeholders! By far the majority of published articles address issues concerning theory, methodology and tools. We admit that these are necessary as in simulation there will always be some need for advancement in these areas, but in this volume?

So what does our second perspective offer? Do articles published in our field give a balance that our textbooks cannot? It appears, at least from our sample set, that in our second perspective we must conclude that there are many articles that concern theory, methodology and tools but few on solving real-world stakeholder-owned problems. Of the latter, there is almost nothing regarding the implementation of these solutions. There is therefore little to aid the graduating student or the simulation practitioner from the perspective of published articles and we might therefore observe that in terms of problem-solving in simulation that there is a hiatus in simulation publishing. Why is this the case? In our next section we explore this from our third perspective, the editorial policies of our four journals.

\section{THE EDITORIAL PERSPECTIVE}

Our previous sections have developed the perspectives that simulation textbooks provide a good but model-solving foundation to burgeoning simulation modelers and that published articles in simulation provide little in the way of good examples of problem-solving but focus on theory. Why is this the case? To shed light on this we now consider our third perspective, the editorial policies of each of our four journals.

\subsection{SIMULATION}

In the editorial policy of SIMULATION, or specifically Simulation: Transactions of The Society for Modeling and Simulation International, it states that it consists of two distinct sections: methodology and applications. It requires that published articles must have "a clear relevance to modeling and simulation issues." It goes on to state that it "aims to help professionals and researche[r]s, particularly those involved in multidisciplinary projects, apply advances in modeling and simulation theory, methodology and technology to their applications areas." Of the two sections, the Methodology section "...welcomes original papers of lasting value dealing with contributions to the modeling and simulation field that are methodological in nature." Encouragingly it also states that "General approaches, formalisms, algorithms, or techniques should preferably be illustrated with significant applications that demonstrate their applicability to real-world problems."

The Applications section "...welcomes applied papers describing mature work involving computational accounts of modeling and simulation." This section also requires that "Proposals for new ways of looking at modeling and simulation must include demonstrations of effectiveness."

\subsection{Simulation Modelling Practice and Theory}

Simulation Modelling Practice and Theory “...provides a forum for original, high-quality papers dealing with any aspect of systems simulation and modeling." It "... aims at being a reference and a powerful tool to all those professionally active and/or interested in the methods and applications of simulation." In regards to our question, the journal solicits papers "...on: theoretical aspects of 
Paul, Eldabi, Kuljis, and Taylor

Table 2: Article Analysis

\begin{tabular}{|l|l|l|l|l|l|}
\hline Journal & \multicolumn{1}{|c|}{ TOMACS } & \multicolumn{1}{c|}{ SIM } & \multicolumn{1}{c|}{ S\&G } & \multicolumn{1}{c|}{ SMPT } & \multicolumn{1}{c|}{ Total } \\
\hline No stakeholder owner & $15(100 \%)$ & $45(88.2 \%)$ & $13(92.9 \%)$ & $25(89.3 \%)$ & $98(90.7 \%)$ \\
\hline Stakeholder owner & $0(0 \%)$ & $6(11.8 \%)$ & $1(7.1 \%)$ & $3(10.7 \%)$ & $10(9.3 \%)$ \\
\hline Some solution? & $0(0 \%)$ & $5(83.3 \%)$ & $1(100 \%)$ & $2(66.7 \%)$ & $8(80 \%)$ \\
\hline Implemented? & $0(0 \%)$ & $0(0 \%)$ & $0(0 \%)$ & $0(0 \%)$ & $0(0 \%)$ \\
\hline Total & 15 & 51 & 14 & 28 & 108 \\
\hline
\end{tabular}

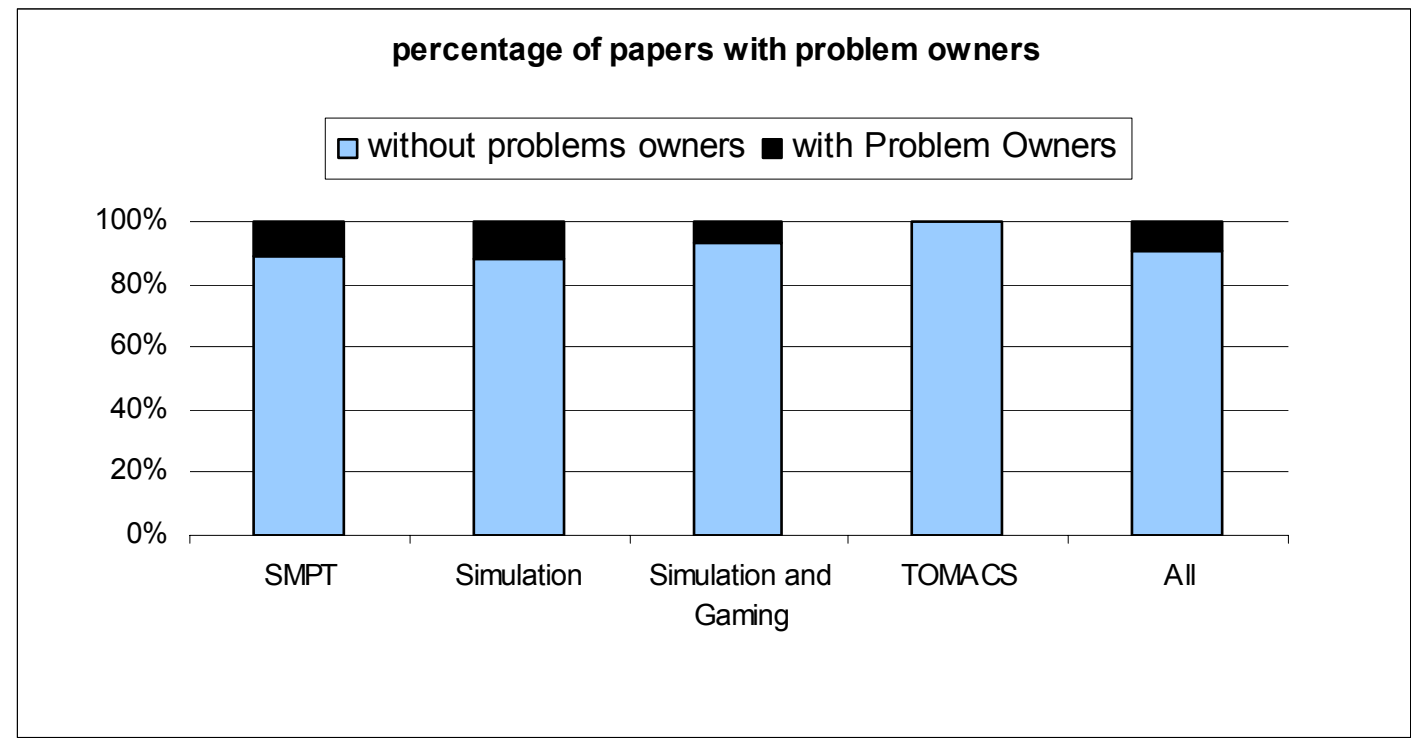

Figure 2 Percentage of Papers with Stakeholder Problem Owners by Journal

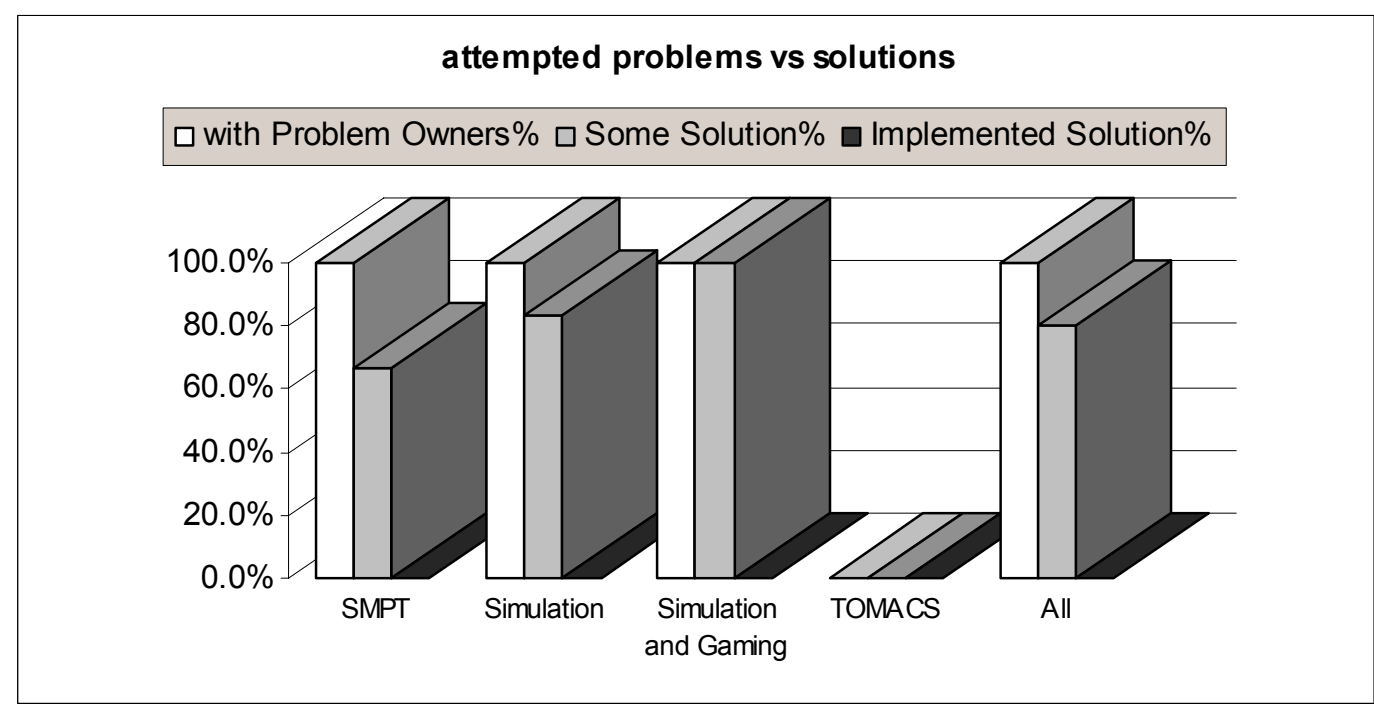

Figure 3 Percentage of Attempted Solutions vs. Implementation by Journal

modeling and simulation; methodology and application of modeling and simulation in any area, ..." Additionally, "Papers covering applications should be presented in such a way that the separate steps in the process, such as model development, computer implementation of the derived model, mathematical and scalability problems encountered and validation/verification with real data become transparent to all readers. Theory may play an important role in a paper, but it should be presented in the context of its applicability to the work being described. For applicationoriented readers it is essential that theoretical papers should cover the following aspects: why the theory is relevant and 
how it can be applied, what is the novelty of the approach and what are the benefits and objectives of a new theory, method or algorithm; what experience has been obtained in applying the approach and what innovations did result?"

\subsection{Simulation \& Gaming}

Simulation \& Gaming is perhaps the oldest journal in our area. It claims that it is "... as a leading international forum for the study and discussion of simulation/gaming methodology used in education, training, consultation, and research." Further, it claims to examine "...the methodologies and explores their application to real-world problems and situations."

\subsection{Discussion}

What do we observe overall? Clearly, each journal claims to have some leaning towards practice. ACM TOMACS wishes to "...improve the practice..." and welcomes "...many types of article including case studies." SIMULATION "aims to help professionals... ....apply advances in modeling and simulation theory, methodology and technology to their applications areas." Further, the two sections of SIMULATION require that articles “...preferably be illustrated with significant applications that demonstrate their applicability to real-world problems[.]" (Methodology) and "[p]roposals for new ways of looking at modeling and simulation must include demonstrations of effectiveness[.]" (Applications). Simulation Modelling Practice and Theory “....aims at being a reference and a powerful tool to all those professionally active..." and in terms of practice requires that "[p]apers covering applications should be presented in such a way that the separate steps in the process, such as model development, computer implementation of the derived model, mathematical and scalability problems encountered and validation/verification with real data become transparent to all readers[.]" and "[f]or application-oriented readers it is essential that theoretical papers should cover the following aspects: why the theory is relevant and how it can be applied,... ... what experience has been obtained in applying the approach and what innovations did result?" Finally, Simulation \& Gaming examines “...the methodologies and explores their application to real-world problems and situations."

Of the above we might argue that ACM TOMACS is the least practice-oriented. Our limited survey agrees with this with all papers dealing with non practice-related topics. The other three have some clear emphasis on the application of simulation. For example, SIMULATION aims to help professionals, SMPT those professionally active, and $\mathrm{S} \& \mathrm{G}$ explores real-world problems (S\&G). However, the editorial scope and policies of all these simulation journals are to some extent practice-oriented. The lan- guage of these differ but there are indications of a desire to publish case studies, help professionals and to explore realworld problems. Our third perspective must be that simulation journals appear to welcome articles that could be very useful to those seeking advice on problem-solving in simulation.

\section{A COMBINED PERSPECTIVE}

Our discussion in this paper began with our outline of our emerging worry. Repeating it here, simulation is about problem solving, assisting, understanding, facilitating, the handling of change, etc. Simulation usually involves a model. Problems only exist if they have owners. A problems only exists for as long as its owners believe they still have a problem they want help with. If the owners decide they know what to do, there is no problem. Hence,

$$
\text { problem existence }=\text { owner's attention span }
$$

However, we take the position that simulation practitioners concentrate more on the model that they create and not the problem. The question we there have asked is, "Is problem solving, or simulation model solving, mission critical?" To answer this we considered three perspectives. These are

\subsection{The Textbook Perspective}

When a simulation practitioner begins their career they have a "natural" bent towards solving the model and not the problem. That is to say simulation textbooks provide an excellent foundation, but where then do students of simulation turn to find what to do when they practice simulation in anger? Where can they find advice that leads them to solve problems and not

\subsection{The Article Perspective}

There are many published articles that concern theory, methodology and tools but few on solving real-world stakeholder-owned problems. Of the latter, there is almost nothing regarding the implementation of these solutions. We might therefore observe that in terms of problemsolving in simulation that there is a meaningful silence in simulation publishing.

\subsection{The Editorial Perspective}

The editorial scope and policies of simulation journals are to some extent practice-oriented. The language of these differ but there are indications of a desire to publish case studies, help professionals and to explore real-world problems. We must observe that simulation journals appear to welcome articles that could be very useful to those seeking advice on problem-solving in simulation. 


\subsection{A Combined Perspective}

Let us present our combined perspective. The Textbook Perspective provides a firm foundation from which modelers gain an understanding of the methods of simulation but not the practice. The Editorial Perspective appears to show that our lead journals extend both the theory and practice of simulation so that our foundation can be built upon with clearly documented experience taken from published articles on problem-solving. However, the Article Perspective negates this. Our limited but sufficiently adequate review of a year's publishing in our field shows there is little in the way of published wisdom that can make real our building. Our Combined Perspective must therefore be that despite good intentions our community tends towards a model-solving culture than a problem-solving one. Let us now consider why.

\section{PROBLEM SOLVING OR MODEL SOLVING?}

"Is problem solving, or simulation model solving, mission critical?" Is our community a model-solving one or a problem-solving one. Which appears to be naturally more mission critical? Our combined perspective leads us to believe that despite good intentions, potential practitioners leave educational courses with a "model-solving" view of the world. Our discussion of published articles and editorial policies has highlighted split between the realities and expectations of publishing. Simulation journals appear to be a rich potential source of problem-solving advice but in reality are not. This is supported by observations from our limited review that show our four simulation journals as dedicating only around $10 \%$ of their output to topics with a clearly identified stakeholder-owned problem. It appears that practitioners when they begin their careers are launched on a path of model-solving with little to bring them round to a problem-solving orientation.

What of simulation publishing? In our review we repeatedly encountered different themes in publishing. We have already identified the $10 \%$ that represent problemoriented (but with no implementation) articles. Others were focused on theory, methodology and tools. Most presented interesting propositions and additions to these areas. However, there were some instances of articles that we, for the purposes of an enthusiastic debate, classify as follows. I can out math you

Articles that "misuse" mathematics to prove a point when a simple description, model or intuition would have sufficed.

\section{Castle confections build on sand}

Articles in which a problem is investigated and solved with no clear stakeholder-owner and arguably therefore no relevance.

\section{A better mouse trap}

There are instances where an article attempts to develop a new approach, tool or technology based on a previous one. The article makes no real contribution as the previous approach, tool or technology can solve the problem (if it exists!) adequately.

\section{Use and abuse of statistics}

Papers that apply rigorous statistical methods to the review of a domain to conclude substantially "obvious" observations.

It would be surprising if as a community we objected to a rich set of articles that show the successful use of simulation. Indeed, this is exactly the perspective presented by simulation editorials where they encourage the submission of interesting articles that would concern the practitioner. However, there is a clear gulf between expectation and reality. Is it just that as a community we are not working on practical problems? Anecdotally, we must say that this is not the case! But why is this not "feeding" publishing. Whether it is a case of being somewhat unrealistic in the review process or that practitioners do not publish is worthy of debate. Either way, it appears there is little to refute our perspective that our community has leaning towards a model-solving, and not problem-solving, mission critical culture.

\section{CONCLUSION}

This paper has considered how do we address problems and models in the practice of simulation? How mission critical are these? We have presented a possibly contentious observation that simulation model solving seems to be more critical to the mission of simulation modeling than problem solving. To investigate this, we have repeatedly asked the question, "Is problem solving, or simulation model solving, mission critical?" against from three perspectives, those of the textbook, the article and the editorial. This has led to our Combined Perspective that textbooks in our area provide an excellent foundation and our journals give the potential to build well advised approaches to problem-solving with simulation. However, the articles reviewed in 2004 have little substance to support this view. We therefore hold the perspective that our community does in fact have a leaning towards a model-solving, and not problem-solving, mission critical culture.

It is hoped that this paper will provide the stimulus for a vigorous debate at this Winter Simulation Conference.

\section{REFERENCES}

Hlupic, V., and Paul, R. J. 1994. Simulating an Automated Paint Shop in the Electronics Industry. Simulation Practice and Theory 1 (5): 195-205. 
Law, A. M., and Kelton W. D. 2000. Simulation Modeling and Analysis. Third edition. Boston: McGraw-Hill.

Paul, R. J., Eldabi, T., and Kuljis, J. 2003. Simulation Education Is No Substitute For Intelligent Thinking, In Proceedings of The 2003 Winter Simulation Conference [online]. Available via http: / / www . wintersim. org/prog03.htm\#ED.

Tocher, K. D. 1963. The Art of Simulation. London: English Universities Press.

\section{AUTHOR BIOGRAPHIES}

RAY J. PAUL is a Professor of Simulation Modelling, Director of the Centre for Applied Simulation Modelling, creator of the Centre for Living Information Systems Thinking, all at Brunel University, UK. He received a B.Sc. in Mathematics, and an M.Sc. and a Ph.D. in Operational Research from Hull University. He has published widely, in books, journals and conference papers, many in the area of simulation modelling and software development. He has acted as a consultant for a variety of United Kingdom government departments, software companies, and commercial companies in the tobacco and oil industries. He is the editor of the Springer-Verlag Practitioner book series. His research interests are in methods of automating the process of modelling, and the general applicability of such methods and their extensions to the wider arena of information systems. He is currently working on wider aspects of simulation, in particular in Web-Based Simulation and the new Grab-and-Glue modelling technique. His email address is ray.paul@brunel.ac.uk. Professor Paul has Parkinsonism, but insists on working part-time because he enjoys it.

TILLAL ELDABI is a lecturer at the Department of Information Systems and Computing at Brunel University, UK. He received a B.Sc. in Econometrics and Social Statistics from the University of Khartoum. He received his M.Sc. in Simulation Modelling and his Ph.D. from Brunel University. His research is in aspects of healthcare management and the intervention of simulation and his main research also concentrates on the economy of healthcare delivery. He is looking to exploit the means of simulation on the wider information systems management area to assist in problem understanding. Dr. Eldabi's email address is tillal.eldabi@brunel.ac.uk.

JASNA KULJIS is a Reader in the Department of Information Systems and Computing at Brunel University. She gained her Dipl. Ing. degree in Theoretical Mathematics from the University of Zagreb, Croatia. She gained her M.S. in Information Science from the University of Pittsburgh, USA, and a Ph.D. in Information Systems from the
London School of Economics, University of London. Her current research is in Human Computer Interfaces. She is mostly interested in the design of graphical user interfaces and in the development of new paradigms that would further enhance the usability of interactive computer systems. She is Director of the VIVID Research Centre at Brunel University. Dr. Kuljis' email address is jasna.kuljis@brunel.ac.uk.

SIMON J E TAYLOR is a Senior Lecturer in the School of Information Systems, Computing and Mathematics and is a member of the Centre for Applied Simulation Modeling, both at Brunel University, UK. He is also a Visiting Associate Professor at the Parallel and Distributed Computing Centre at Nanyang Technological University in Singapore. He is also chairs ACM SIGSIM, the Simulation Study Group of the UK Operational Research Society and the COTS Simulation Package Interoperability Product Development Group (CSPI-PDG) standards body at SISO. $\mathrm{He}$ is joint editor-in-chief of the Journal of Simulation. He the general co-chair of the UK Simulation Workshop Series and is a steering committee member of PADS. He also Ford Simulation Technical Advisor and consults to industry on aspects of simulation. His main research interests are distributed simulation and applications of ICT to simulation modeling. His email address is simon. taylor@brunel.ac.uk. 